\title{
Renewing Art Education Philosophy in Light of Twenty-First Century Skills
}

\author{
Masuda Aalim Jalan Qurban ${ }^{1}$ \\ ${ }^{1}$ Faculty of Education, Department of Art Education, King Saud University, Kingdom of Saudi Arabia \\ Correspondence: Masuda Aalim Jalan Qurban, Associate Professor. Tel: 96-65-0540-8805. E-mail: \\ profmasudaqurban@gmail.com
}

Received: February 3, 2019

Accepted: February 21, 2019

Online Published: February 28, 2019

doi:10.5539/ass.v15n3p107

URL: https://doi.org/10.5539/ass.v15n3p107

This is a research project that was supported by a grant from the Research Center for the Humanities, Deanship of Scientific Research at King Saud University, 2019.

\begin{abstract}
The problem of renewing the philosophy of teaching art education in the light of 21st century skills. Art education at the global level is facing many and many challenges as a result of the tremendous changes in the way knowledge and information are exchanged, in which technology plays a large role because of the necessity of its existence at various scientific levels. These challenges required a comprehensive review of the educational system and philosophy in general And in particular technical education, which in turn lead to the development of advanced courses and innovative work to prepare a learner is able to absorb better, in addition to it makes the educational process an interesting process for the learner and by integrating those courses study With 21st century skills and information technology, which in turn improves the outcomes of the learning process and the quality of education.
\end{abstract}

Research problem: The researcher found through the study of international and international research of the 21st century skills and information technology to be applied in the curricula of different fields, because it is important for the students as it earns and trains them on life and work skills to bring out a person who is more capable of dealing smartly in life and linking them to the curriculum. As well as their application to the labor market.

Therefore, the problem of this research lies in the following question: To what extent is it possible to implement a program based on the integration of information technology and art education curricula in the light of 21st century skills to bring out a learner capable of keeping pace with the labor market?

Research goals: The research aims to:

- Prepare a student capable of keeping pace with the labor market through the application of the skills of the 21st century by international standards in the curricula of art education.

- to highlight the skills of the twenty-first century of high value that contribute to the output of a learner capable of achieving professional success in the labor market.

Research importance:

- keep up with information technology through integration with the curriculum of art education

- Use the skills of the twenty-first century in teaching the curriculum of art education

- Stimulate educational institutions to apply the skills of the twenty-first century and mechanisms to achieve the vision of the Kingdom 2030 in the field of education.

\section{Introduction and Background}

\subsection{Introduction}

Globally, art education faces numerous and increasing challenges, and that is due to the tremendous changes that happened to the method of exchanging knowledge and information which technology plays a major role in, given the necessity of its inevitable existence among the different educational stages. These challenges require a comprehensive review of educational philosophy and systems in general and art education in particular. This 
calls for finding advanced and renewable educational curricula that work on developing learners who are able to comprehend better, as well as making the educational process exciting for the learner through integrating those curricula with twenty-first century skills and information technology. This leads to improving the objectives and quality of the educational process's outcomes.

Art education plays an essential role in advancing the educational process and the development of future skills through "the development and assessment of learners as a positive individual of society, where art education works on expanding the learner's culture, developing their expression skills, and contributing to the integration of their mental, psychological, behavioral, and social formation"'Al Saud,2006, in order to harmonize between abstract knowledge and practical experience in the labor market.

Where "nowadays, art education stands in front of the streams and trends of contemporary art forms that result from cumulative experiences that went through the steps of art education development to form standards within the field.", Al Amri (2015). Education in general and art education in particular hold a significant role in changing, developing, improving, and growing all aspects of society. Education, "as viewed by the Arab organization of education, culture, and science, is the overall development of all of its human and economic aspects, and it is the doorway to technological and scientific civilizations, with the human as the mean and the end of it all”. (Al Shareef, 1979).

Education within this context is considered as "a collective work in a specified time and place, and a response to the development demands of a specific society as required by the social demands and needs in general, and development in particular. And since education is the cultural representation in all its different aspects, curricula are the tools to achieve the general objectives of education". (Hashim, 1987).

Education and its curricula for any society "were in fact results of the type of common philosophy within that society in all its different cultural, social, economic, political, and spiritual contexts. Defining a society's paths, intellectual and economic trends, as well as historical and cultural assets, in turn defines its educational objective as well as its educational approaches. Learning cannot occur without depending on clear and specified objectives and that are strongly connected to the philosophy of the society. Deciding the goal of education is strongly connected to the goal of life, so philosophy decides what is viewed as the goal of life, while education suggests means to achieve that goal”. (Rusk, 1929).

"In the twenty-first century, which is the century of the abundance of productivity and dominance of information technology, educational systems have a dire need for finding a common ground that connects between the requirements of businessmen, industries, education, and society in light of understanding the meaning of twenty-first century skills in a way that contributes to preparing students for life, learning, and working in this digital age.” (Husni, 2007).

\subsection{Research Problem}

Upon reviewing global and international researches of twenty first century skills and information technology, the researcher realized the importance of applying those skills and technologies in the different fields of education curricula for its importance to learners. They provide and train them in life and work skills in order to produce a more able person who is more able to deal intelligently with life and link between the skills and educational curricula among many specializations besides applying them in the labor market.

The problem of this research lies within the following question:

To what extent can a program based on the integration of information technology and art education curricula in light of twenty-first century skills be applied to produce learners who are capable of keeping up with the labor market?

\subsection{Research Objectives}

This research aims to:

1. Prepare students who are able to keep up with the labor market through the application of twenty-first century skills by its international standards in art education curricula.

- Highlight valuable twenty-first century skills that contribute to producing learners who are capable of achieving professional success in the labor market.

\subsection{Research Significance}

[1]. Keeping up with information technology through its integration with art education curricula.

[2]. Using twenty-first century skills in teaching the art education curriculum. 
[3]. Motivating education institutions to apply twenty-first century skills and their mechanisms to achieve the Saudi Kingdom's vision 2030 in education.

\subsection{Research Hypothesis}

The research postulates that through the application of a program based on the integration between information technology and art education curricula in light of twenty-first century skills, it is possible to produce a learner who is able to keep up with the labor market.

\subsection{Research Method}

This research follows a descriptive method in the theoretical aspect and an experimental method in the practical aspect.

\section{Framework}

\subsection{Theoretical Framework}

Follows the descriptive method and includes:

- $\quad$ Studying twenty-first century skills

- Objectives of art education in light of twenty-first century skills

- Learning outcomes and indicators of education in the twenty-first century

- The definition of E-learning

- $\quad$ Types of E-learning

- $\quad$ Properties of E-learning

- $\quad$ Objectives of E-learning

- Levels of E-learning

- $\quad$ Features of E-learning

- Disadvantages of E-learning

\subsection{Practical Framework}

Follows the experimental method and includes:

- Research sample

- $\quad$ Research tools

- Designing the proposed educational program

- The followed teaching strategies of the proposed educational program

- Steps of preparing the proposed educational program

- $\quad$ Timeframe of the proposed program

- $\quad$ Suggested topics for the program

- Choosing the educational subject

- Preparing associated subjects

- $\quad$ The followed assessment style in the proposed program

\subsubsection{Theoretical Framework}

Since the 70's, education pioneers have been exposed to scientific theories that serve the art education field for the purpose of crossing the gap between research and application, and between science and art in art education. "Art education philosophy became either precisely defining concepts and terms used in art education, or through using objective thinking more than self thought. Also, renewing the education philosophy forms a basis for the advancement of art education, and is a result of matching art education to artistic and creative development through the use of scientific and technological advancement.” (Ahmad, 2006).

The modern vision of learning, its curricula, methods and ways has emerged. However, this modern vision appeared to be affected by the type of common philosophy in society (governance tool philosophy). According to this, the definition of curricula was defined as a collective of educational experiences that schools make available for their students in and out of them with the intention of helping them grow their characters among all various aspects in a way that is consistent with the educational objectives." (Sarhan, 2008). 
Even though that "there are tireless efforts to come up with a broad and comprehensive definition for education, efforts are still governed by the limited and private intended purpose of education. Most educational objectives that exist in the world today are based on preconceived education templates, and they unite according to the type of experiences and their availability, as well as the quality of producing individuals as an end result of this adopted planning” (Zacharias \& White, 1964).

Arab countries, similar to other developing countries, have withheld useless educational formulas that are "almost entirely exotic to our educational systems, and this type of education can only -according to those formulas- happen through years of traditional education and its basis should be the classroom, the teacher, and the textbook. If we tried to briefly touch on the subject of the educational crisis in the Arab world today that is due to the confusion, failure, and experimentations that have no scientific basis nor a political outlook of governance tools, we would realize the (great secret) behind the concept of education and cultural revolution, Falquthi (2005). Some research results found that the current educational system is unable to meet the needs of the country such as technical, managerial, and professional personnel in terms of quantity and quality of provided materials (Moustafa, 1972).

The twenty-first century has witnessed a far-reaching shift in perception of education in general, as well as the perception of both the relationship between education and focusing on developing the brain and not the knowledge on one hand, and the entirety of experience not only in terms of knowledge and its integrity, but in terms of society needs on the other hand. The purpose of education is not limited to preparing aware and versed on knowledge, but preparing someone who is able to compete and succeed in life and work not only on a national level, but on an international level. The objectives of education have evolved as a result of their sequencing, which stems from the continuous economic, social, and cultural revolutions across the ages. This confirms the start of agricultural revolution age to conceptual revolution age in the twenty-first century.

The conceptual revolution age started as a result of production abundance in information technology governance. The goal of education within it aims to prepare creative empathizers whose activity is not limited to left brain associated knowledge, but also are able to engage the right side of the brain which is responsible for the ability to absorb available knowledge; not only verbal knowledge. However; all types and forms of languages whether verbal, audio, visual, technological, media, scientific, artistic, or creative are also able to transform traditional knowledge into an idea and a new invention that challenges, modifies, and adds to all types of different knowledge.

Mutawaa (2010) adds that "education in the twenty-first century aims to prepare someone who is able to gain the highest levels of flexibility, quick thinking, risk taking, controversial cases, and learning through exploration, trial and error, individual responsibility, dealing with the possible and the unknown. Also, dealing with reality and virtual and symbolic worlds, as well as shifting from directed learning to self and remote learning, besides improving their ability to create, imagine, and taste.” (Mutawaa, 2010).

"The field of visual arts was a race to confirming twenty-first century skills, where many studies confirmed that focusing on one of the brain's sides, which is the left side, was not enough for education. Instead, basic skills and abilities should be engaged in the conceptual revolution age such as creativity, renovation, empathy, inspiration, and the ability to link between elements and events to create something new, which is the job of the right brain." (Sudqi \& Mutawaa, 2009).

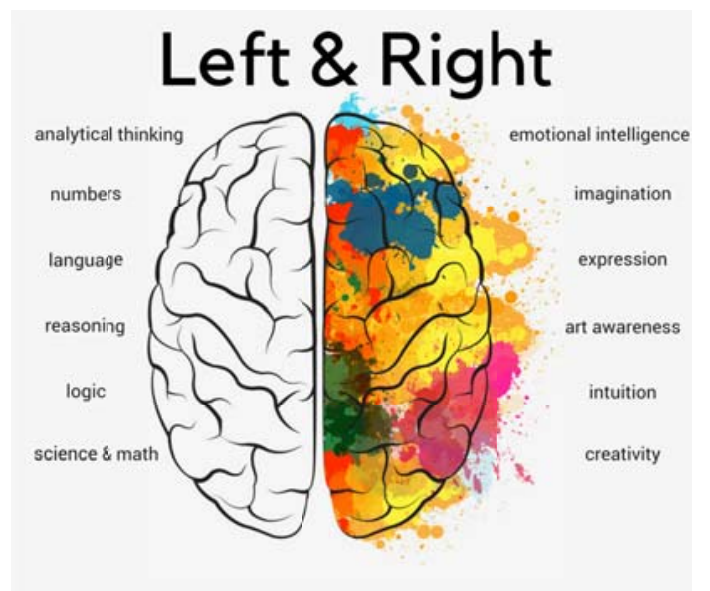

Figure 1 shows the use of thinking in the right brain 
The right brain is responsible for creativity and art, so it specializes in templates, patterns, perception, and real and imaginative images. It also views things as one unit, and gathers and comprehends all parts of a situation in one whole image, so it specializes in induction instead of inference. This part of the brain is the center of instinct and imagination. Based on the above, the researcher was able to conclude Figure 1 which shows the use of the right side of the brain in thinking.

Creative art skills are essential skills that develop normal successful personalities by what they add to them such as calm sensations, strength of personality, concentration, and clarifying the difference between calculated risk and mindless recklessness, insofar as they use intelligence and planning in dealing with mysterious situations so they can be confronted and directed for desired purposes. Scientific research found that artistic activities are a thinking tool, and were then considered the main hub for many studies and projects where arts are used constantly and regularly in developing mental and general skills in education and edification.” (Sudqi, 2011). These skills are dependent on by information technology, so the researcher will, in this study, depend on these skills to try and change the philosophy of traditional art education through the use and integration of innovative tools in teaching art education in light of twenty-first century skills.

\subsubsection{Twenty-First Century Skills}

Nassif defines twenty-first century skills as "effective opportunities about the modality of learning with others and using knowledge in innovating new knowledge and continuous learning and the ability to use available technology." (Nassif, 2011) "They are the skills and abilities that qualify students to succeed and accomplish tasks in their society which are represented in the ability to achieve communication, cooperation, and effective information exchange to solve problems and the ability to adapt, innovate, and develop through the use of digital technology to keep up and match the needs of the century.” (Kathem, 2017).

The importance and role of technology and technological and information skills have been proven as essential skills for success and effective learning in light of developing and changing societies, as well as a supporting tool for creativity. A report done by Partnership for twenty-first Century Skills with cooperation from the American Association of Colleges of Teacher Education titled "Unleash the Future," teachers discussed the importance of using technology, its tools, and its different application in the education process (educational system) and setting plans and strategies that allow the integration of technology within school curricula. Statistics showed that when students use technology in the educational process, it makes them more enthusiastic and excited to learn by a percentage of 51\%, apply their knowledge of practical problem and learn through context by $30 \%$, and property learning by $23 \%$. Also, teachers pointed out in this report that technology has an effective and an influential role in developing students' skills in the twenty-first century that include creativity and development by $39 \%$, communication and cooperation skills by $30 \%$, and critical thinking and problem solving skills by $27 \%$, which qualifies those students and improves their skills and abilities to succeed in the future and their work." (Nitham, 2017).

2.2.1.2 Objectives of Art Education in light of Twenty-First Century Skills (Niham, 2017)

1. Qualifying learners to be able to achieve their goals and future plans through the development of mental, artistic, scientific, and advanced thinking skills, and help them adapt to the different life situations.

2. Understanding the characteristics of ores and employ them with processes and techniques to produce individual or collective expressional artistic works (drawing, photography, carving, and sculpting) and other utilitarian and applied works such as the various design concepts (porcelain, textile, printing, design and metal ignition) that were based on a knowledge and conceptual artistic base.

3. Developing linguistic and visual skills through understanding visual and fine arts from a historical and civilizational point of view.

4. Testing and assessing a wide range of topics, symbols, and ideas to solve environmental and social problems.

5. Observing and assessing traits and features of self and others' art works.

6. Connecting between fine visual arts and arts and other fields of knowledge.

7. Creating visual art products that depend on interaction and exploration through the use of technology and multimedia with the scientific engagement of normal and digital electronics.

8. Initiating teamwork, the role of social cooperation, and production of small art crafts while effectively engaging in small art projects.

9. Training for research and investigation skills about information and knowledge that stimulate thinking. 


\subsubsection{Education Outcomes and Indicators in the Twenty-First Century (Sudqi, 2009)}

- $\quad$ Self-directed learners

- Collaborative workers

- $\quad$ Effective communicators

- Community contributors

- Quality producers

- $\quad$ Complex thinkers

The above clarifies that learning with no application and gaining of twenty-first century skills is an incomplete system that does not achieve goals that go hand in hand with coexistence in the twenty-first century and keeping up with modern technological changes and the digital revolution.

We must look into educational curricula and the importance of integrating twenty-first century skills within them and provide school necessities to apply them. This in return creates students who are able to take responsibility and coexist in the age of modern technology. The researcher will explain the definition of E-learning, the most up-to-date information technology tool, to use it in applying the research program.

\subsubsection{Definition of E-learning}

E-learning includes many broad applications, such as: Internet based learning, computerized learning, Satellite broadcast, remote learning, virtual learning, interactive television, CDs and others, (Hung, 2002): Despite this variance, we notice the link between this definition with the Internet and applications on the Internet, which makes the definition more linked to remote learning that depends on the Internet. Oweid (2001) defines E-learning as "education that targets finding an interactive environment that is rich with applications that depend on computers and internet, and enables trained students to reach learning resources any time, any place."

Al-Musa and Al-Mubarak define it as "the way of learning that uses modern communication tools such as computers and computer network, as well as multimedia whether audio, visual, paintings, search engines, electronic libraries, and internet gates whether remotely or in the classroom; it is using all forms of a tool to deliver information to the learner in a short period of time and with less effort and more benefit." (Al Mubarak, 2005).

Al-Oraify defines it as "presenting educational content including its explanations, exercises, interactions, and follow-ups partly or wholly in the classroom or remotely through advanced programs saved on computers or on the Internet." (Al Oraifi, 2003).

The researcher sees that the above definitions have differences due to the difference in the viewpoints of those who talked about E-learning. The reason might be that E-learning is a new concept that has transpired enough, or due to the fact that it contains two principal sides, which are the technical side and the educational side, and that requires that who ever integrates the two should have a complete vision. It is also noted that most of the definitions view E-learning happening only outside of the classroom and that it does not require any specific place. The boundaries of place should be cancelled just like those of time, and E-learning cannot be limited to a certain place as Al-Musa claims "the definition of E-learning also includes using the tools inside the classroom." (Al Musa, 2007). Which is also what the researcher agrees with, where she sees that E-learning includes all of it. The researcher also seems that E-learning is not just a technical educational tool that is used outside of classrooms and schools, but should be used interactively inside the classroom, as it is a tool that grabs the students' attention, in addition to it being up to date with twenty-first century skills.

\subsubsection{Types of E-learning}

E-learning can be categorized into the following types:

1. Internet based E-learning, which divides into two types:

Synchronous: where all students registered for the curriculum as well as the registered teacher sign into a specific website on the internet at the same time, where students and teachers can start discussions.

Non-synchronous: where students sign in at any time depending on needs and proper timing.

\section{Non-internet based E-learning}

This includes most electronic multimedia that is used in educations such as programs, TV channels, and E-books. E-learning can be categorized based on its use on classroom, as the researcher seems the importance of such a categorization and its closeness to be applied in our educational reality as previously shown in the definition of 
E-learning which can be categorized into the following types:

1- Classroom E-learning (direct):

This type of E-learning is based on the use of E-learning applications inside the classroom where there is a direct interaction between the teachers and his students, where they engage this technique in this interaction to achieve the most sum of educational outcome. (Al Shahrani, 2017).

2- Non-classroom E-learning (indirect)

This type of E-learning is done outside traditional schools and classrooms (remotely) and can be divided into two types depending on the decided timing of learning as mentioned in the above categories:

A. Synchronous non-class E-learning: which is the type that E-learning is done at a specific time where students meet with their teacher through E-learning applications.

B. Non-synchronous non-classroom E-learning: Students and teachers do not have to agree to a specific timing, so students sign into the different E-learning applications to learn and receive messages from teachers and students depending on appropriate timings. Then, teachers sign in to upload new educational material or answer students' questions and assign them homework at the right times.

\subsubsection{Characteristics of E-learning}

The Internet has helped grow interests in these programs for their ability to transcend geographical and time boundaries, as well as their enormous supply of information in a digital environment that is available for everyone with the a relatively low cost. E-learning applications help break psychological boundaries between teachers and learners, fulfill the needs and characteristics of the learner, and raise revenue from investment by reducing the cost of education, E-learning has a special importance compared to traditional educational tools and that is due to the many characteristics that are linked to it and can be summed up in the following: (Al Musa, 2009).

1. Provide digital content for curricula in a multimedia environment such as written texts, spoken, sound effects, art clips, moving pictures, static images, video clips, etc.

2. The easiness of providing digital educational content through multimedia that depend on computers and networks, which integrate with each other to achieve certain educational objectives.

3. Easiness and flexibility of continuous updating for educational curricula with the ability to keep up with scientific advances without any additional costs. Not to mention that the curricula in its digital form are unable to get damaged and consumed duo to use unlike printed curricula.

4. Achieve a higher level of interaction between the learner on one side, and the teacher, content, classmates, educational institution, programs and applications on another side.

5. E-learning applications provide access and benefit to it regardless of time and place or any other boundaries that might stop the learner from communicating and engaging in the educational process.

6. E-learning applications provide the ability to preview curricula through viewing the latest levels, or reviewing past curricula to achieve the most educational benefit.

7. E-learning applications enable learners to continuously assess themselves through direct exams optionally to measure the level of learning.

\subsubsection{E-learning Objectives}

E-learning applications are common with traditional educational tools in terms of general goals that focus on preparing an educated generation that has enough skill and experience that it is eligible to meet the requirements of professional life. However, the necessary ways and tools to achieve this goal might differ from one time to another. Skills and knowledge that were required in the 20th century are totally or relatively different from the skills that are required in the twenty-first century. So the objectives of E-learning applications are focused to achieve the following: (Al Shahrani, 2009).

1. Provide multiple and various resources of information that allow comparison, discussion, analysis, and assessment opportunities.

2. Reshape the educational process by defining the roles of teachers, learners, and the educational institutions.

3. Using E-learning applications to link and interact within the educational system (teacher, learner, educational institution, home, society, and environment.) 
4. Exchange educational experiences through E-learning applications.

5. Develop the skills and abilities of students and build their characters to prepare a generation that is able to communicate well with others and interact with the changes of the century through modern technical tools.

6. Spread the technical culture in a way to help create an electronic community who is able to keep up with the modern developments.

\subsubsection{Levels of E-learning}

E-learning levels can be categorized into four major categories as the following (Al Musa, 2009).

1. Enrichment level: which is the use of the Internet as a source for general information as well as specialized information that is spread over the different websites, where learners can benefit by supporting their achievement and gain skills, which is a level that is based on learner's desire to improve their knowledge and information, or by getting instructions from the teacher to enrich the learner's skills and information.

2. Supplemental level: in this level, learning is done in traditional classroom, but benefits are gained from the internet as a source of education, learning, and specialized experiences that are designed, produced, and made available on the internet.

3. Essential level: In this level there is a total dependence on the internet in learning, where an E-learning system is designed and provided with its requirements, then curricula are designed in addition to the learning, interaction, and communication tools and are made available at private websites for the educational institution on the internet.

4. Integrated level: This level includes, in addition to the previous levels, what is linked to digital visualization of the teacher while instructing which is made available on the website to interact with and connect synchronously or otherwise. Additionally, there is a benefit from the other linked information sources that are made accessible to the teacher through the website, as well as accessing digital libraries, laboratories, museums, and others.

\subsubsection{Characteristics of E-learning}

Muhaisen, Al-Musa, and Al Shahrani claim that E-learning has characteristics and benefits that are called benefits, features, or justifications of E-learning, which include (Al Muhaisen, 2002):

1. E-learning allows students to take a major part of this process, not a secondary one.

2. Develops students' self-learning and continuous learning skills, as well as researching information.

3. Helps providing a private atmosphere for students to give them an opportunity to learn depending in their ability without fear or shyness of classmates.

4. Provides a chance for constant communication between students and curricula all the time.

5. Saves a lot of time wasted by students when going to school and back, as well as between lectures.

6. The ability for students to communicate between themselves, and with their teachers, through different channels.

7. E-learning makes education more appealing and exciting for students.

8. E-learning allows for the ability to deliver knowledge through different visual, audio, or read mediums.

9. It is possible to teach larger numbers of students through E-learning.

10. Contributes to the exchange of experiences and point of views amongst students.

11. E-learning makes students feel equal in terms of educational opportunity, discussion, and giving opinions.

12. E-learning allows learning without having to commit to actual attendance and what it bears of difficulties for some students.

13. Easiness and variety of ways to assess student-learning development.

14. E-learning helps develop thinking and enriches the learning process.

15. Provides freedom and courage for students to express themselves.

16. This type of learning is considered

17. This type of learning suits unavailable adults who have jobs that do not allow them to directly attend classes. 


\subsubsection{Drawbacks of E-learning}

Even though E-learning has many features, it still has drawbacks that limit its effectiveness or use, such as:

1. E-learning does not focus on all senses; it only focuses on hearing and sight without the rest of the senses.

2. E-learning needs to build infrastructure such as devices, factories, and internet connection lines.

3. It requires intensive training for teachers and students to use modern technology prior to the application of E-learning.

4. It needs teachers who are highly eligible to deal with the technological developments that are used in this type of learning, as well as an eligible management that can do the process, in addition to specialists to prepare and design the educational programs.

5. E-learning lacks human interaction between teachers and students, and between students themselves.

6. Societies in some countries view E-learning graduates as less qualified.

\section{The Researcher's Framework}

Based on the above, the researcher aims to design a proposed educational program based on pairing art education objectives and information technology skills, which are represented in E-learning that depends on the Internet and is synchronous in light of twenty-first century skills.

The philosophy of the suggested educational program focus on:

1. The philosophy of art education.

2. The philosophy of E-learning and characteristics of college of education students.

3. The philosophy of twenty-first century skills.

\subsection{Research Sample}

Third year students at the college of education who study metal design.

\subsection{Research Tools}

Designing a survey to figure out the opinions of specialists in art education about the technological tools in the twenty-first century that could help with the educational process. Appendix (1)

\subsubsection{Designing the Proposed Educational Program}

In this topic, the researcher discusses the educational design of the proposed program that is based on combining art education objectives and information technology skills in light of twenty-first century skills.

\subsubsection{Teaching Strategies Used in the Proposed Educational Program}

For the development of the educational process, the researcher chose to combine the following teaching strategies when designing the proposed program of study, which are the following:

1. E-Questioning Strategy: questions are a dynamic process done within the classroom, which are verbal actions carried out by the teacher in writing or orally to manage the dialogue and discussions between students, enhance their interaction, test their learning, or provide them with new knowledge (Azmi, 2014).

2. E-Discussion Strategy: this strategy is one of the most important communication tools and interaction in E-learning environment, through which many educational objectives can be achieved. It can be defined as a strategy that allows users to communicate by sending topics to members to read and comment on either linearly or in a thread. It also achieves many of the educational objectives that many educational institutions seek, where when students participate in ideas, learning reachers the highest levels of knowledge, especially analysis, composition, and assessment. Additionally, students add their personal experiences to each other.” (Moustafa, 2014).

Through this method, the teacher can know his level of success in teaching and whether his/her students have understood the material or not, and can also expose weaknesses and strengths. The discussion method essentially depends on the teacher and the students, and on the level of interaction and cooperation between them in order to reach facts and objectives, so learners present the axis point in this method.

3. E-Brainstorming: Munir Al Husari and Yousef Al Onaizi (2000) defined E-brainstorming as "a style of creative thinking that aims to stimulate thought, spark the mind, and create ideas, adopt them, and propose multiple solutions. This means the use of mental potential to solve a particular problem, which 
is a technique used by a group of individuals to find solutions for a certain problem by collecting ideas that are spontaneously perceived by them (Al Husari \& Al Onaizi, 2000.

4. E-Cooperative learning strategy: this strategy creates a dynamic learning environment within learning environments and include interactions between two or more students, and it is one of the most effective methods that provide students with experiences and various skills. Cooperation is an informal but effective learning tool, where there are some important characteristics that are achieved through cooperative learning such as:

- Students acquire the ability to work within university and cooperative environments.

- Enriching communication and critical thinking skills.

- Two-way interactions.

- Collective relationships that arise are important in the dynamics and ethics of the group.

- Progress and quality of work.

5. E-Problem solving: "this method aims to help the learner so that he can understand the basic cognitive concepts in solving educational problems that may be encountered. It also helps learners to direct their behavior and abilities. The strategy of problem solving in education can be applied through posing a research problem for students on the course page where they are asked to employ what they have learned to solve the problem, but individually. Also, each student can discuss with the teacher through E-mail or dialogue, and can propose a research problem that the teacher can choose and discuss with learners and give each learner a chance to show their point of view for the solution. Then, solutions are gathered and shared on a discussion board so that there is extensive debate by this solution circulated to all students (Azmi, 2014).

\subsection{Steps of Preparing the Proposed Educational Program}

Time Frame of the proposed program

The proposed program takes three weeks with three lectures, one lecture per week over the course of two days, each lecture is six hours.

\subsubsection{Proposed Topics for the Program}

The researcher selected five topics that were divided into five technical lessons based on areas of art education and information technology skills that are presented in synchronous Internet-based E-learning in the twenty-first century as follows:

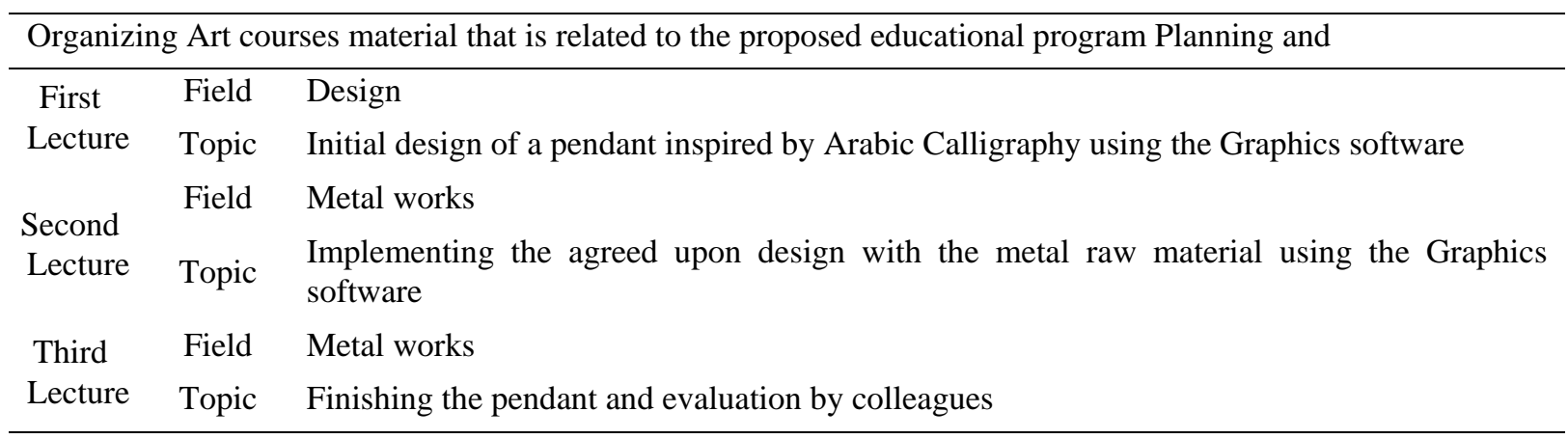

These topics have been chosen because they offer the vital steps to practice artwork in the field of art education which are the ability to which the student can form and develop ideas and use raw materials and tools and respond to visual elements, analysis, interpretation, judging the artwork, and employ modern technology in the twenty-first century to emphasize creativity and innovation, develop problem solving skills and critical thinking and problem solving, communicate, cooperate, actively participate in society and keeping up with the requirements of the digital age.

\subsubsection{Selecting the educational material}

When selecting the educational material, the researcher took into account the following:

- To be suitable for the characteristics, needs, and interests of third year students at the Faculty of Education, King Saud University. 
- $\quad$ To be linked to planning, preparation, implementation, and assessment mechanisms for the planning of unit lessons and art activities in the field of Art education.

- To be specific and appropriate to the proposed teaching strategies.

- To be compatible with the data and components of the tools of contemporary technology and employed in teaching and art production.

The educational material associated with the proposed program was collected from references, websites, related studies, Arab research, and addressing those issues through contemporary information technology and its applications.

\subsubsection{Preparation of Accompanying Materials}

Presenting a collection of photos, videos, presentations, websites, links, mind maps, and images of the main interfaces that illustrate the properties and abilities of the technological applications that are related to the fields and topics of art courses.

\subsubsection{Assessment Method of the Proposed Program}

Designing a questionnaire to explore the views of specialists in art education about the extent of honesty of the objectives and content of the educational program which is based on pairing art education objectives with information technology skills presented in E-learning in light of twenty-first century skills.

\subsubsection{Application of the Program}

The researcher used a range of technology tools in the twenty-first century and the questionnaire results have come out positive for the use of these tools in the teaching process and teaching metal design for third year students at the Faculty of Education. Based on the above, the researcher selected Facebook as a tool to help students communicate, share, and cooperate with each other, in addition to selecting Graphic as an art production tool in the design stage. As for the production and assessment stages, the researcher picked Instagram through evaluating and presenting artwork on an audience, in addition to the students' assessment of themselves and each other. The results were as follows:
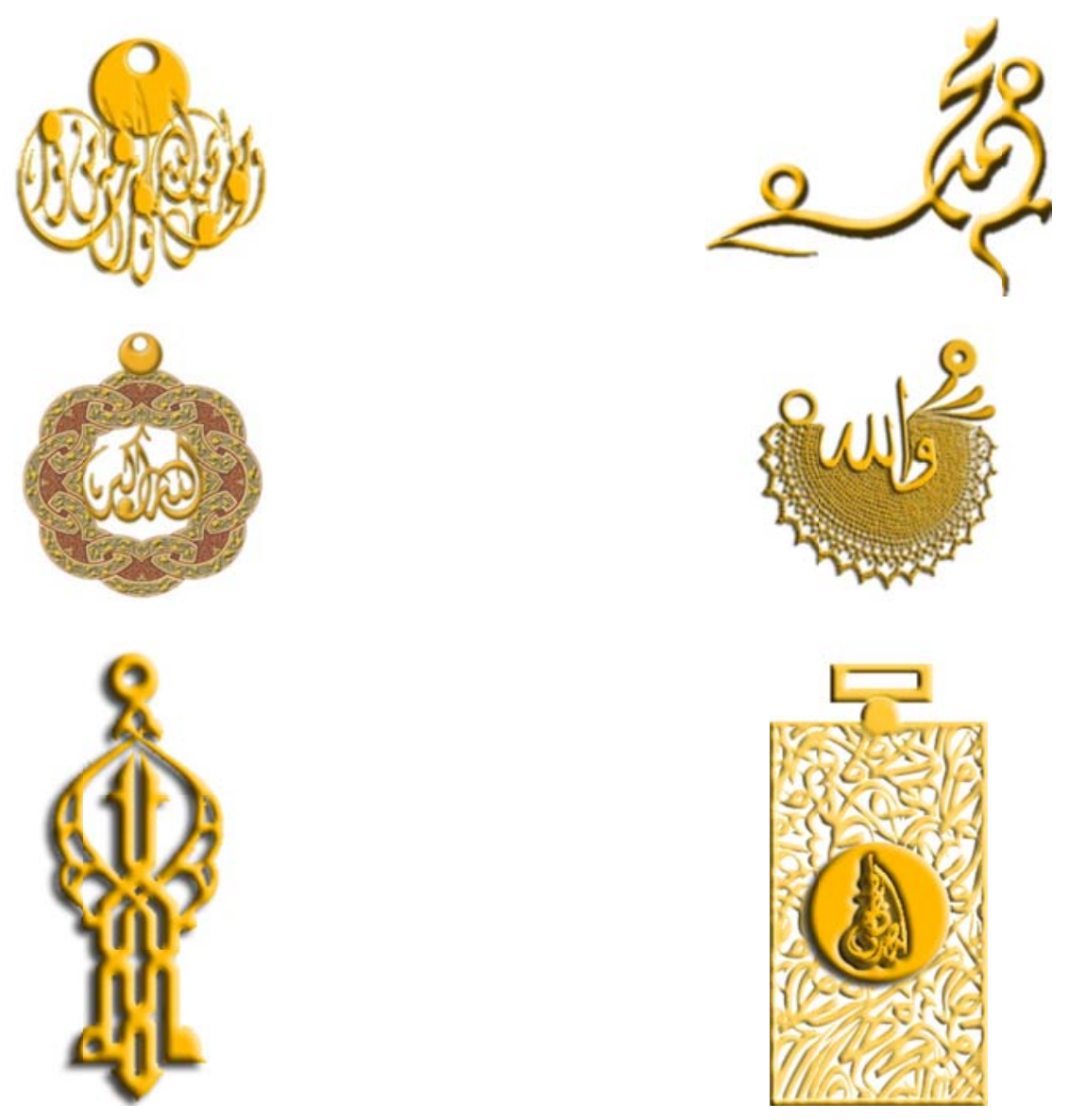


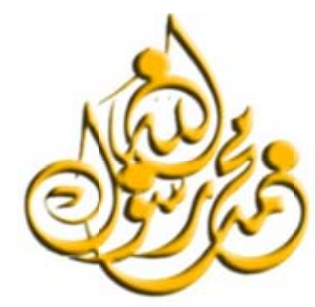

Figure (2: 8). Some of the students’ artwork using the Graphics software

\section{Suggestions and Recommendations}

In light of the results of the current study, the researcher recommends and suggests the following:

1. Holding training seminars continuously by educational leaders to find the most important issues and requirements of the age and discuss them in light of educational programs worked on by art education teachers.

2. The need to keep pace with scientific and technological progress and link it with educational innovations in the art education field and benefit from the advantages provided by the concept of globalization in the current era, with no omission to address the cumulative negativities of the effects of technology in art education.

3. The need to include strategic planning programs as training courses for art education teachers and field leaders for the purpose of good planning and educational renewal of the educational philosophy in art education. Where it includes compatibility between the modern requirements and capabilities while taking into account the spirit of art and the educational process in art education.

4. Expand the rules of renewal and decision-making among the educational leaders in the field of art education.

5. The need for the renewal to include a directed educational system based on the improvement, efficiency, and performance of art education teachers through the development of the academic educational process at the university level and ensuring communication with graduates, taking the principal of life-long learning to ensure growth of experiences, knowledge, and skills, which positively reflects on the field of art education as a whole.

\section{References}

Ahmad, G. (2006). An objective look on preparing Art educators in art education college (Published Research). Informatics and learning systems conference, University of Cairo.

Akram, M. (2014). E-learning Strategies. E-learning Journal, Al Mansora University, 13.

Al Amri, M. (2015). Contemporary trends in art education. Literature and social sciences Journal, 34, 56-66.

Al Dimirdash, S., \& Munir, K. (2011). Curricula. Egypt: Daar Al Oloom publishing.

Al Husari, A., \&Al Onaizi, Y. (2000). Working teaching methods. Kuwait: AlFalah Publishing.

Al Muhaisen, I. (2002). E-learning: Luxury or Necessity. Worksheet presented to the Future school conference held at King Saud University.

Al Oweid, M. (1993). E-learning in the college communications and information at Riyadh - Case Study. Worksheet presented to the E-learning conference. Al-Faisal schools, Riyadh.

Al Saud, K. (2005). Art education curricula between theory and pedagogy. Oman: Daar Wael Publishing.

Al Shareef, M. (1979). Strategy for developing education, "Report of the strategy committee for developing education in Arab countries." Arab organization of education, culture, and sciences.

Al-Musa, A., \& Al-Mubarak, A. (2005). E-learning: Principals and application. Riyadh: Information network.

Al-Oraifi, Y. (2003). E-learning as a promising and pioneering tool. A worksheet presented to the first conference for E-learning, King Faisal schools in Riyadh.

Al-Zuhairi, T. (2009). Strategy for the Application of E-learning Programs in Iraqi Universities, Proceedings of the First Scientific Conference of the Iraqi Society of Information Technology. Department of Information 
and Libraries. Al-Mustansariya University, Baghdad.

Azmi, N. (2014). E-learning technologies. Cairo: Al Fikr Al Arabi Publishing.

Hashem, M. (1987). Modern trends in education. Articles about new education intellect and sustainable education. Egypt: Aldaar Al Jamahiriya Publishing.

Jerread, R., \& White, S. (1964). The Requirements for Major Curriculum Revision. In R. W. Heath (Ed.), New Curricula. New York, Harper and Row Publishers.

Kathim, Sh. (2017). An educational program based on pairing technological and art teaching skills in the twenty-first century for art education college students (Unpublished Masters Thesis). College of Art education, Halwan University.

Mohammad, H. (2005). Network Education System. Cairo: The World of Books.

Moustafa, M. (1972). Skilled Labor in Economic Development the Libyan Case (Unpublished Masters Thesis), Dept. of Economics, University of California.

Mutawaa, M. (2010). The effectiveness of using mind maps in developing education that is consistent with brain functions in art education. Education and Arts Journal, 29(29).

Rusk, R. (1929). The philosophical Vases of Education. U.K: University of London press.

Sudqi, S. (2011). The role of art in developing mind habits in the twenty-first century, cultural conference for the children of the national children cultural center. Ministry of Culture.

Sudqi, S., \& Hosni, D. (2010). Future Visions of the Role of Art and Technology in Twenty-first Century Skills. Education, 45, 22-28.

Sudqi, S., \& Mutawaa, M. (2009). The Power of Art and Thinking. Cairo: National Children Cultural Center.

Sudqi, S., \&Hosni, D. (2009). The Role of Twenty-first Century Skills as an Effective Strategy for Creating Jobs. The Annual Conference of the Faculty of Quality Education, Al-Mansora University.

Tan, S., \& Hung, D. (2002). Beyond Information Pumping: Creating a Constructivist E-Learning Environment. Educational Technology Journal, 3, 22-28.

Tawfiq, S. (2011). Designing a portfolio for art education to develop observation for a kindergarten teacher in light of 21st century skills and measuring its effect. PhD, Faculty of Art Education, Halwan University.

\section{Appendix}

A questionnaire to explore the opinion of experts in art education about technological tools in the $21^{\text {st }}$ century that can help in the educational process. Please read the terms of the questionnaire and give an opinion on the main and sub axes by marking a check in the appropriate field in front of each item, and write any additions or suggestions that you consider.

\begin{tabular}{|c|c|c|c|c|c|}
\hline \multicolumn{2}{|r|}{ Questionnaire Items } & Related & Somewhat & Unrelated & Notes \\
\hline $\begin{array}{l}\text { Technological tools } \\
\text { in the 21st century }\end{array}$ & Definition & & & & \\
\hline \multicolumn{2}{|c|}{ Communication and Collaborative workspaces tools } & & & & \\
\hline $\begin{array}{c}=\text { Blogger } \\
\text { Blogger }\end{array}$ & $\begin{array}{l}\text { is defined as a user generated dynamic Blogging } \\
\text { web page where content and posts are ranked } \\
\text { chronologically from newest to oldest, } \\
\text { accompanied by a mechanism for archiving old } \\
\text { entries }\end{array}$ & & & & \\
\hline $\begin{array}{l}\text { facebook } \\
\text { Facebook }\end{array}$ & $\begin{array}{l}\text { Facebook is one of the most famous modern means } \\
\text { of communication that helped build a personal } \\
\text { social network to connect many individuals } \\
\text { regardless of their cultures, views, times, opinions, } \\
\text { and attitudes, which allows them to share and } \\
\text { exchange information, opinions, and news with } \\
\text { individuals from within the community and the } \\
\text { outside world quickly and effectively. }\end{array}$ & & & & \\
\hline
\end{tabular}




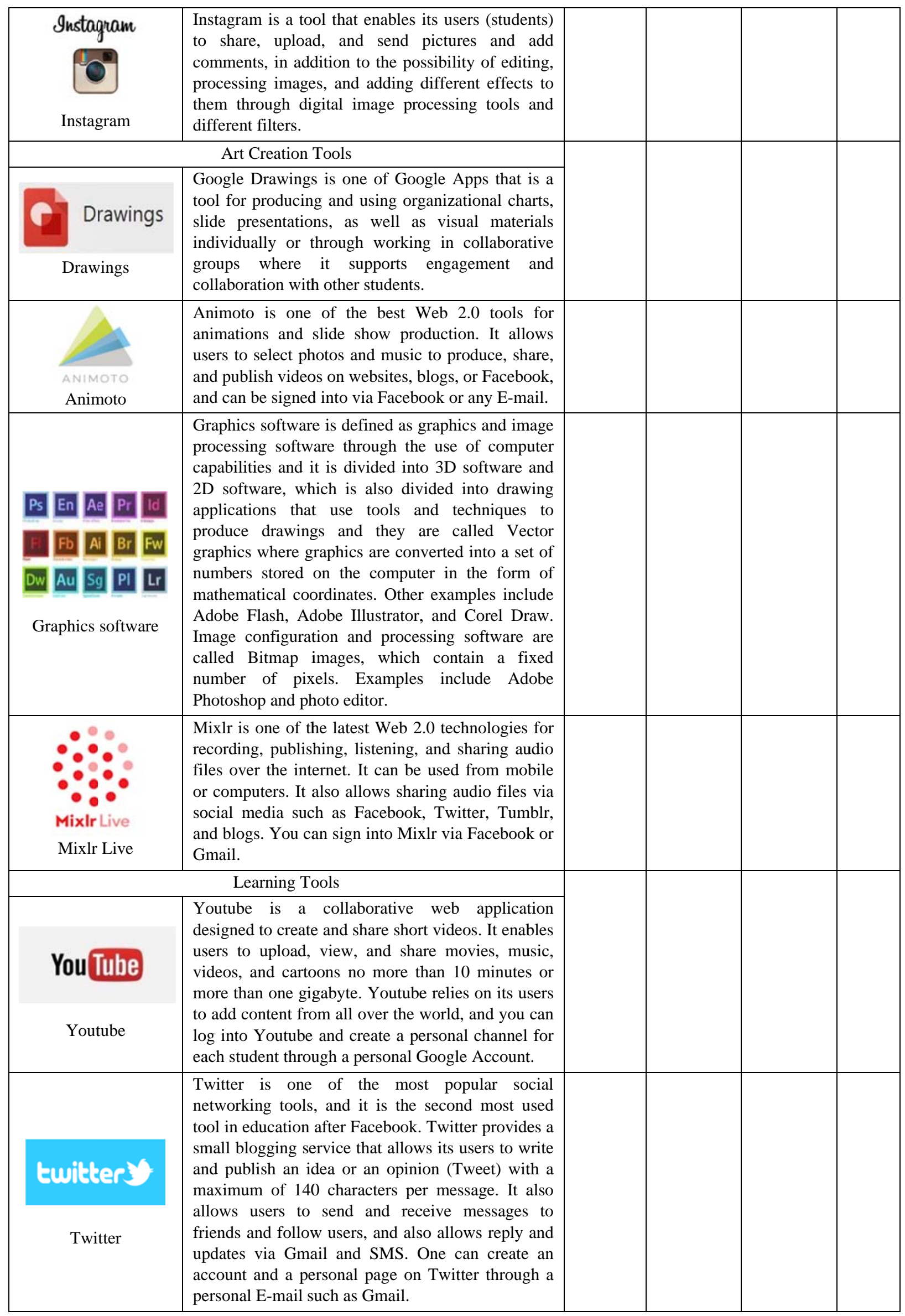




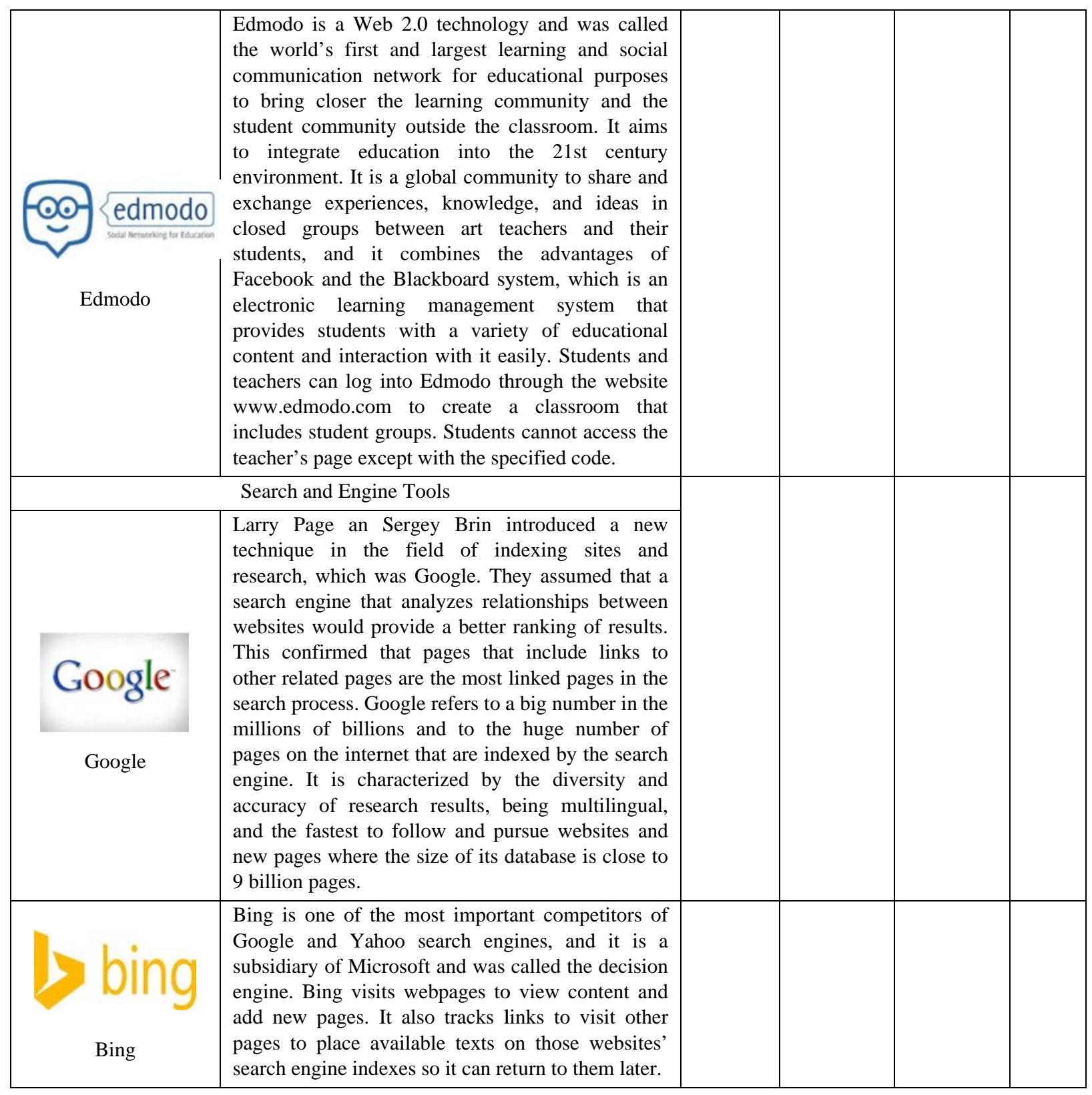

\section{Copyrights}

Copyright for this article is retained by the author(s), with first publication rights granted to the journal.

This is an open-access article distributed under the terms and conditions of the Creative Commons Attribution license (http://creativecommons.org/licenses/by/4.0/). 